\title{
Fundamentos estrutural-fenomenológicos da percepção a partir de Merleau-Ponty
}

\author{
Structural-phenomenological foundations of perception based on Merleau- \\ Ponty
}

\author{
Danilo Saretta Verissimo \\ Universidade Estadual Paulista \\ Brasil
}

\begin{abstract}
Resumo
Neste artigo, evidenciamos e discutimos fundamentos de uma concepção estrutural-fenomenológica da percepção a partir de Merleau-Ponty. Focalizamos investigações do filósofo acerca da organização perceptiva, mais especificamente, sobre a relação entre a propriedade objetivante da percepção e a sua articulação com o fundo perceptivo. Nossa orientação metodológica fundamenta-se na comunicação, observada na obra de Merleau-Ponty, entre a concepção fenomenológica de horizonte perceptivo e do princípio gestáltico de figura e fundo. A argumentação centra-se em três pontos principais: a relação entre a propriedade presentativa da percepção e o campo da sua manifestação a partir de pressupostos fenomenológicos e gestaltistas; a atestação, mediante o exame da crítica à hipótese de constância, da operância silenciosa do fundo perceptivo; e a exploração dos fatores funcionais envolvidos na organização perceptiva.
\end{abstract}

Palavras-chave: percepção; fenomenologia; psicologia da Gestalt; Merleau-Ponty

\begin{abstract}
In this article, we present and discuss the bases of a structural-phenomenological concept of perception based on Merleau-Ponty. We focus on the philosopher's investigations of perceptual organization, more specifically on the relation between the objectifying property of perception and its articulation with the perceptual background. Our methodological approach is based on the communication, observed in the work of Merleau-Ponty, between the phenomenological conception of the perceptual horizon and the Gestalt principle of figure-ground. Our arguments center on three main points: the relation between the presentative property of perception and the field of its manifestation based on phenomenological and gestaltist assumptions; the attestation, through the examination of the criticism against the hypothesis of constancy, of the silent operance of the perceptual background; and the exploration of the functional factors involved in the perceptive organization.
\end{abstract}

Keywords: perception; phenomenology; Gestalt psychology; Merleau-Ponty 


\section{Introdução}

Neste artigo, buscamos evidenciar e discutir as bases de uma concepção estrutural-fenomenológica da percepção a partir de Merleau-Ponty. Nosso foco são investigações do filósofo acerca da organização perceptiva, mais especificamente, sobre a relação entre a propriedade objetivante e presentativa da percepção, e sua articulação com o fundo perceptivo. Nossa orientação metodológica fundamenta-se na comunicação, presente na filosofia de Merleau-Ponty, entre a concepção fenomenológica de horizonte perceptivo e do princípio gestáltico de figura e fundo. Nesse sentido, nosso ponto de partida é mostrar que, em Merleau-Ponty, os fundamentos fenomenológicos referentes ao sujeito corpóreo e à transcendência da coisa e do espaço percebidos, que se integram na categoria fenomenológica da intencionalidade, possuem correspondência com o domínio conceitual da estrutura figura e fundo. Esta via de investigação é reforçada por Colonna (2014), cujo trabalho baseia-se no entendimento de que a lógica dos desenvolvimentos mais próprios da filosofia da percepção merleau-pontiana não devem ser atrelados apenas à teoria husserliana da percepção, mas, igualmente, ao conceito de Gestalt e às contribuições experimentais da psicologia gestaltista. Em seguida, examinamos a crítica à hipótese de constância, ponto central da evolução histórica da noção de forma, o que nos permite estabelecer, juntamente com Merleau-Ponty, uma dimensão de percepção inconsciente, ou de impercepção, própria da organização perceptiva. Esta análise revela o caráter positivo exercido, na percepção, pelos elementos que recuam como fundo da manifestação perceptiva. Por fim, tratamos dos aspectos dinâmicos, ou funcionais, da percepção, com o intuito de circunscrever certos critérios básicos que orientam o ato intencional eletivo de referência a alguma coisa. Nosso ponto de chegada é uma hipótese de trabalho, que deverá ser desenvolvida alhures, e que se refere ao papel da intersubjetividade na percepção.

O presente trabalho é, antes de tudo, um estudo exploratório, com base na obra de Merleau-Ponty, acerca de dimensões fundamentais que possam servir de quadro teórico a investigações sobre a estrutura da consciência perceptiva. Nossa abordagem dos textos do filósofo segue uma orientação temática, sem recurso à disposição cronológica, e sem o intuito de recenseá-los. Mobilizamos, principalmente, a Fenomenologia da percepção (Merleau-Ponty, 1945), as notas de curso recolhidas em O mundo sensível e o mundo da expressão (Merleau-Ponty, 1953/2011) e, por último, A estrutura do comportamento (Merleau-Ponty, 1942/2006), que, a despeito de figurar como a primeira publicação de Merleau-Ponty, possui indicações relevantes sobre os aspectos funcionais da percepção, assunto que, no encadeamento da nossa argumentação, será tratado ao final do texto. 


\title{
Percepção e movimento
}

Destacamos, inicialmente, um trecho da Fenomenologia da percepção (MerleauPonty, 1945) em que importantes elementos filosóficos para uma concepção da organização perceptiva são apresentados conjuntamente:

\begin{abstract}
Ver um objeto é ou possuí-lo à margem do campo visual e poder fixá-lo, ou então responder efetivamente a esta solicitação, fixando-o. Quando eu o fixo, ancoro-me nele, mas esta "parada" do olhar é apenas uma modalidade do seu movimento: continuo no interior do objeto a exploração que, há pouco, sobrevoava-os a todos, em um só movimento fecho a paisagem e abro o objeto. As duas operações não coincidem por acaso: não são as contingências da minha organização corporal, por exemplo, a estrutura da minha retina, que me obrigam a ver a circunvizinhança obscuramente se quero ver claramente o objeto. Mesmo se eu nada soubesse de cones e bastonetes, conceberia que é necessário adormecer a circunvizinhança para ver melhor o objeto, e perder em fundo aquilo que se ganha em figura, porque olhar o objeto é entranhar-se nele, e que os objetos formam um sistema em que um não pode se mostrar sem esconder outros. Mais precisamente, o horizonte interior de um objeto não pode se tornar objeto sem que os objetos circundantes tornem-se horizonte e a visão é um ato de duas faces (pp. 81-2, grifos nossos).
\end{abstract}

Merleau-Ponty (1945) atrela logo a percepção ao movimento, e o campo perceptivo é caracterizado em termos dinâmicos, em referência ao jogo de abertura e fechamento, de fixação e de esquecimento envolvido na percepção de algo. A percepção, com efeito, implica uma potência motora, uma capacidade de adentrar e de explorar a profundidade do mundo percebido. O sistema formado pelos objetos não é o de um mundo objetivo, ou geométrico, que permitiria sua visualização integral, ou ideal, mas o de um campo aberto, em direção ao qual nos projetamos, e no qual a manifestação perceptiva de um objeto corresponde ao encobrimento de outros. Os termos desta relação, a manifestação e o encobrimento, configuram momentos dependentes um do outro, não por acaso, mas por necessidade. Este é o preço da realidade da coisa percebida, afirma Merleau-Ponty $(1933-46 / 1996)^{1}$. Se a sua visibilidade depende de um sujeito da percepção presente no lugar perceptível, por outro lado este lugar não se dá completamente a ele. Nota-se que o rompimento da distância entre o sujeito e o mundo percebido, herdada da modernidade, não implica a

\footnotetext{
${ }^{1}$ O primado da percepção e suas consequências filosóficas (Merleau-Ponty, 1996) reúne uma exposição por parte de Merleau-Ponty diante da Sociedade Francesa de Filosofia, em sessão de 23 de novembro de 1946, bem como o debate realizado em seguida entre o filósofo e diversos arguidores, dentre eles Bréhier, Beaufret e Hyppolite. O conteúdo deste material constitui uma exposição geral de algumas teses fundamentais da Fenomenologia da percepção (Merleau-Ponty, 1945).
} 
confusão entre esses dois polos irrecusáveis da manifestação perceptiva. O recuo do objeto percebido e do restante do campo para além das partes imediatamente expostas é condição da percepção, tanto quanto a presença do objeto a um sujeito perceptivo. Ver é sempre ver de algum lugar, a partir do qual um campo sensível se abre, revelando coisas e possibilidades perceptivas.

A cada instante da aparição de uma coisa permanece, pois, havendo mais perfis dela mesma além daqueles atualmente expostos. Merleau-Ponty (1945), acompanhando as descrições husserlianas da intencionalidade perceptiva, refere-se a essa profundidade do objeto como horizonte interno, que abarca todas as faces que não encontram exposição direta nos diversos momentos da sua presentação. No trecho que destacamos acima, vale frisar, Merleau-Ponty identifica a ideia de objeto à própria ideia de horizonte interno. É este que se torna objeto de percepção, reforçando a concepção de que tudo que aparece comporta uma dimensão de ausência. No limite, a ausência, tanto dos perfis ocultos do objeto quanto dos outros objetos que compõem o horizonte de mundo, ou horizonte externo, funciona como o grande motivo da percepção e do movimento. Há sempre mais para ver em um campo perceptivo. O horizonte perceptivo, embora se estruture em torno de domínios que não encontram exposição aqui e agora, reenvia a momentos integrados ao objeto percebido e aos seus perfis como possibilidade de experiência perceptiva. Trata-se, em outras palavras, de atrelar a "estrutura de horizonte" (Merleau-Ponty, 1945, p. 97) tanto a uma perspectiva espacial quanto a uma perspectiva temporal. A presença do objeto se dá em meio a uma síntese de horizontes perceptivos em que os perfis aparentes sustentam-se nos perfis percebidos agora há pouco, tanto quanto naqueles que estão porvir. O eu vejo assenta-se, portanto, no eu posso ver, dimensão de experiência originária e que contrai elementos sensório-motores, espaciais e temporais. Merleau-Ponty (1933-46/1996) comenta: "o lado não visto [de um objeto] anuncia-se a mim como 'visível alhures', ao mesmo tempo presente e apenas iminente" (p. 48).

Quanto mais distante da circunvizinhança do objeto percebido, no espaço e no tempo, no sentido de experiência possível, mais acentuado fica o caráter presuntivo que marca qualquer percepção. Esta abertura a que está submetida toda coisa percebida é constitutiva da sua "realidade". Não se trata de um objeto possível ou necessário, como no caso do objeto de um ato intelectual (Merleau-Ponty, 193346/1996). O objeto e o espaço são percebidos na medida em que escapam continuamente ao sujeito perceptivo, configurando sua transcendência em relação a este. 


\section{Variações em torno da estrutura figura e fundo}

A percepção ocorre, portanto, como fenômeno de estrutura "objeto-horizonte", ou, conforme escopo conceitual igualmente adotado por Merleau-Ponty (1945), dessa vez em referência à psicologia da Gestalt, como fenômeno de estrutura figura e fundo. O recurso de Merleau-Ponty à psicologia da Gestalt não é um acaso. A relação necessária da figura com o fundo exprime a irredutibilidade da exposição ambígua e parcial das coisas na manifestação perceptiva (Barbaras, 2001). Merleau-Ponty interessa-se, ademais, pela dimensão científica da noção de Gestalt. Na psicologia da Gestalt, a teoria da percepção é perpassada pelo recurso ao teste factual das relações entre partes e todos, aspecto essencial na medida em que a estrutura, em qualquer nível, perceptivo, orgânico ou físico, denota uma organização que reúne valor e existência, significado e arranjo contingente de materiais (Merleau-Ponty, 1942/2006).

A distinção entre figura e fundo perceptivo é atribuída a Edgar Rubin (Koffka, 1935/1975). Ela envolve o estudo da "formação de 'uma figura 'sobre' ou 'dentro de' outra'" (Koffka, 1935/1975, p. 188), o que exige, em primeira instância, a investigação das forças figurais, da continuidade do fundo e da relação de dependência funcional da figura em relação ao fundo. Simondon (1964-5/2013) resume o inventário realizado por Rubin acerca das diferenças fenomenais entre figura e fundo. Destacamos as seguintes: I) A figura possui uma forma, ou seja, o caráter de unidade, estabilidade e constância de um objeto, enquanto o fundo aparece sem dimensões e estrutura próprias, o que lhe confere a qualidade de indeterminação. Nessa dinâmica, a figura apropria-se do contorno que a distingue do fundo. II) $\mathrm{O}$ fundo parece estender-se continuamente por detrás da figura, que, por sua vez, se impõe em plano dianteiro. III) Desse modo, a figura causa maior impressão, sendo mais facilmente recordada e mais apta a sugerir uma significação. Elementos com significação definida, como as palavras da voz humana, impõem-se facilmente como figura e, quando se encontram no plano de fundo, geram certo incômodo perceptivo, justamente em razão da sua tendência a ocupar o lugar figural. IV) Dada uma certa estrutura figura e fundo, a percepção do mesmo campo com inversão dos elementos que ocupam estas funções equivale à uma percepção nova e distinta da primeira. V) A estrutura figura e fundo desenvolve-se temporalmente. Apresentações muito breves de imagens, em taquistoscópio, não permitem a distinção entre figura e fundo.

Das considerações tecidas na seção anterior, decorre que a estrutura figura e fundo implica a aparição da identidade do objeto, com o correlativo recuo do fundo perceptivo, e que a unidade da coisa percebida se dá como uma "série aberta de experiências" (Merleau-Ponty, 1945, p. 270) cuja ambiguidade perene sustenta, no 
limite, todo ato de atenção perceptiva. Os aspectos dos objetos que recaem na percepção implicam apenas uma "parada momentânea no processo perceptivo" (Merleau-Ponty, 1945, p. 269), posto que configuram, ao mesmo tempo, uma convocação a perceber mais e mais.

Voltemo-nos, justamente, a esta pausa do processo perceptivo, que não é interrupção senão metaforicamente. Podemos denominá-la, juntamente com MerleauPonty (1945), como um ato de atenção, "a constituição ativa de um objeto novo que explicita e tematiza o que até então não era ofertado senão a título de horizonte indeterminado" (p. 39). Seguindo de perto as pesquisas da psicologia da Gestalt, Merleau-Ponty (1945) afirma que um dado perceptivo apenas pode aparecer "no meio de outra coisa" (p. 10), como parte de um campo. Nele, a figura perceptiva, a forma, no sentido da identidade de objeto percebido, não se encontra pré-figurada à espera de um olhar atento que a ilumine. Atentar para um objeto, destacando-o a título de figura, implica uma nova articulação, ou configuração, do campo. Se o fundo, ou horizonte, estende-se além da figura, é apenas na medida em que faz parte do mesmo gênero de ser desta última, nota Merleau-Ponty, o que implica atestar que, pela conversão do olhar, o horizonte pode fazer-se objeto e o objeto recuar como fundo perceptivo. Fazem-se presentes, aqui, elementos da maior importância, referentes à questão acerca dos aspectos funcionais da organização perceptiva, que abordaremos adiante com mais detalhes. O que se mostra como condição da percepção é a estrutura figura-fundo, sem que isso determine a existência de sentidos perceptivos pré-determinados. A configuração objetal depende de fatores próprios à relação concreta entre o sujeito da percepção e o mundo circundante. Merleau-Ponty (1945) fala, por exemplo, da dependência que se observa, nos animais, entre a estrutura e o sentido biológico da situação, e, no caso da percepção humana, do peso das intenções do sujeito que "se refletem imediatamente no campo perceptivo, polarizando-o, ou marcam-no com seu monograma, ou, enfim, fazem nascer nele sem esforço uma onda significativa" (p. 153). Por outro lado, há de se considerar as forças fenomenais autóctones que agem, por exemplo, no campo visual, impondo o privilégio de constituição de determinadas formas em detrimento de outros componentes do campo, que permanecem operando como fundo da figura percebida. Sabe-se que diversos fatores, como orientação espacial, tamanho relativo, simplicidade e simetria, destacados pela escola da Gestalt, agem na articulação da dinâmica entre figura e fundo.

O caráter situado da atividade intencional perceptiva responde à natureza corpórea do sujeito da percepção. A dinâmica de presença e ausência que caracteriza tanto a identidade dos objetos quanto a profundidade do campo do qual eles fazem parte assenta-se na possibilidade de podermos contornar as coisas e explorar o 
espaço. Esta é a razão para Merleau-Ponty (1945) chamar o corpo de "pivô do mundo" (p. 97). A estrutura figura e fundo subentende um terceiro termo, afirma o filósofo: o corpo próprio. Merleau-Ponty (1945) escreve: "toda figura se perfila sobre o duplo horizonte do espaço exterior e do espaço corporal" (p. 117). Ao invés da estrutura figura-fundo, deveríamos falar, pois, da estrutura fundo-figura-fundo, especificando que, de uma parte, se trata do horizonte corporal, presença tão originária no que diz respeito ao campo perceptivo quanto a identidade de objetos e seus horizontes temporais e espaciais. A localização do corpo no espaço, ponto zero da percepção, e suas modalidades sensoriais e motoras são elementos que, como o fundo perceptivo, são recalcados em prol do direcionamento às coisas e às tarefas que realizamos cotidianamente. Nas palavras de Merleau-Ponty (1945), o espaço corporal é "o termo não-percebido para o qual todos os objetos voltam sua face" (p. 97), "a obscuridade da sala necessária à claridade do espetáculo" (p. 117). Seu funcionamento sinérgico e anônimo sustenta nossa "inerência a um mundo" (p. 97). A versão merleau-pontiana da suspensão do realismo ingênuo, ou seja, da redução fenomenológica, exigida por Husserl, envolve, justamente, a tematização da intencionalidade corpórea. A este propósito, Merleau-Ponty (1945) observa: "dirigindo-me para um mundo, esmago minhas intenções perceptivas e minhas intenções práticas em objetos que, finalmente, me aparecem como anteriores e exteriores a elas" (p. 97). Quando o corpo se torna, todavia, foco da nossa atenção prática, tal como quando aprendemos a dançar, a praticar um novo esporte ou quando adoecemos, nossa disponibilidade para as coisas é temporariamente afetada e a corporeidade apresenta sua qualidade de presente inescapável. Já a atenção teórica endereçada a ele, no quadro da suspensão do realismo ingênuo, revela-o como sujeito de toda atividade intencional.

Importante destacar que o corpo e suas funções também podem ser pensados com base na estrutura gestáltica de figura e fundo. Para Goldstein (1934/1983), cujo estruturalismo organicista teve grande influência sobre os fenomenólogos, principalmente sobre Merleau-Ponty, a precisão funcional das mais diversas atividades corporais subordina-se à necessidade de que as regiões envolvidas nessas operações encontrem-se num primeiro plano em relação ao restante do organismo ${ }^{2}$. Por exemplo: o ato de olhar atentivamente para alguma coisa depende do destaque funcional dos órgãos da visão, sem que este processo se desprenda de todo um jogo muscular que envolve a espinha dorsal, o pescoço e os braços, fundo corporal da atividade em foco.

\footnotetext{
2 Sobre a vinculação da obra de Goldstein com a fenomenologia, remetemos o leitor ao livro intitulado Kurt Goldstein: psiquiatria e fenomenologia, organizado por Silva (2015).
} 
Em suma, a percepção de objetos no espaço ocorre em meio a um campo perceptivo, de modo que a manifestação perceptiva de um objeto implica o encobrimento de outros. O recuo do horizonte e das partes ocultas de um objeto evidencia o caráter situado da percepção, além de ressaltar a dimensão de ausência que caracteriza a experiência perceptiva e alimenta o movimento do sujeito percipiente. Com efeito, a percepção fundamenta-se em um poder perceber continuamente, na medida da potência motora do sujeito e da transcendência da coisa percebida. Estes são elementos básicos de uma filosofia fenomenológica da percepção. Na psicologia, faz-se referência à estrutura de figura e fundo da percepção. A atenção focal a uma figura perceptiva representa uma configuração do campo de percepção, e depende de fatores intrínsecos à relação entre o sujeito e o meio circundante. O corpo é parte originária neste processo. A anonímia das funções corporais reforça a ideia, correspondente à estrutura figura e fundo, de que a percepção envolve a experiência da presença além do expressamente percebido.

\section{Crítica à hipótese de constância}

Para avançarmos na compreensão da relação entre objeto e horizonte, entre figura e fundo, vale examinar a crítica à hipótese de constância, tema que perpassa as análises realizadas por Merleau-Ponty (1945) nos primeiros capítulos da Fenomenologia da percepção. Merleau-Ponty observa que a psicologia da percepção clássica mantém-se sob influência do dualismo entre as sensações, tomadas como matéria da percepção, e fatores subjetivos responsáveis pela produção, ou organização, do tema perceptivo. Este dualismo liga-se à hipótese de constância, pressuposto segundo o qual deve haver "correspondência pontual e uma conexão constante entre o estímulo e a percepção elementar" (Merleau-Ponty, 1945, p. 14), quer dizer, entre os estímulos físicos e os dados sensoriais. Em outras palavras, na hipótese de constância subentende-se uma equivalência entre a identidade das sensações e a identidade dos estímulos. A riqueza de formas possíveis de agrupamento perceptivo, tal como experimentada por nós, seria, de acordo com este pressuposto, prova da natureza não sensível da produção do tema perceptivo. Não houvesse produção subjetiva superior, como um ato de atenção ou de julgamento, nossa experiência permaneceria restrita à correlação entre estímulos e sensações. As pesquisas da psicologia da Forma, que operam a crítica à hipótese de constância, mostram, todavia, que a atividade perceptiva, pressupõe uma organização autóctone das condições do campo sensorial, e não uma determinação de parte por parte, com estruturação devida a atividades superiores. 
Esta divergência entre as categorias clássicas e a psicologia estrutural pode ser esclarecida com o recurso à discussão, por parte de Koffka (1922), de um problema de percepção exposto por Stumpf $\left(1883^{3}\right.$ citado por Koffka, 1922). Considerem-se três estímulos $a, b, c$, em que $a>b>c$, e aos quais correspondem três sensações: $A$, B e C. O exemplo vale para qualquer tipo de estímulo e de sensação. No caso em apreço, a sensação $A$ não pode ser distinguida de $B$, nem $B$ de $C$, ao passo que se pode perceber a diferença entre as sensações $A$ e $C$. Stumpf afirma que, embora pareçam equivalentes, $A$ e $B$ e $B$ e $C$ são distintos em realidade, posto que $A$, $B$, e $C$ advêm de estímulos de intensidades diferentes. Parece contraditório, portanto, afirmar-se que $A=B, B=C$, mas que $A \neq C$. $A, B$ e $C$ referem-se a dados de consciência, e não a estímulos, de modo que, em face do paradoxo, se deveria atestar a possibilidade da existência de diferenças dadas entre sensações que, em virtude de fatores atencionais, não são percebidas. Nesta linha de pensamento, deveríamos considerar, ainda, sensações não percebidas, a despeito de figurarem como dados de consciência. Para Stumpf, a ideia de sensação não consciente acarreta uma contradição. Toda sensação, em correlação com os estímulos externos, é um dado de consciência, que, contudo, pode não ser percebido.

Koffka (1922), ao contrário, mostra que, no problema em questão, há três conjuntos de experimentos: a comparação entre $A$ e $B$, entre $B$ e $C$ e, finalmente, entre $A$ e $C$. Segundo ele, só há contradição caso a sensação seja considerada "uma função do seu estímulo isolado" (p. 538), o que evidencia a conservação da hipótese de constância em sua forma estrita. Se uma sensação, entretanto, for tomada como "função do cenário experimental geral" (p. 538), a contradição se desfaz. Em vista do cenário experimental, ao estímulo a correspondem as sensações $A_{1}$ e $A_{3}$, ao estímulo $b$, as sensações $B_{1}$ e $B_{2}$, e ao estímulo $c$, as sensações $C_{2}$ e $C_{3}$, de modo que $A_{1}=B_{1}$, $\mathrm{B}_{2}=\mathrm{C}_{2}$, e $\mathrm{A}_{3}>\mathrm{C}_{3}$. O retorno à "experiência mesma" (the experience itself) (Koffka, 1922, p.540) evidencia, no caso dos pares de sensações $A_{1}$ e $B_{1}$, e $B_{2}$ e $C_{2}$, o que Gurwitsch (1957), que analisa as conclusões de Koffka, chama de experiência plana (expérience plane), ao passo que o par de sensações $A_{3}$ e $C_{3}$ acarreta a experiência de variação. Koffka e Gurwitsch utilizam, no inglês e no francês, respectivamente, as palavras step e décalage para se referir a esta experiência de movimento. De um lado, temos experiência de repetição, de permanecer em um mesmo nível perceptivo. "A experiência plana é de natureza essencialmente estática", assevera Gurwitsch (1957, p. 107). De outro lado, temos experiência de uma escala, ou de uma gradação, com movimento ascendente ou descendente. Em um caso, o estímulo $c$ faz parte de um contexto estático, no outro, de um contexto dinâmico. Koffka encerra a

\footnotetext{
${ }^{3}$ Stumpf, C. Tonpsychologie. v.1. Leipzig: Hirzel, 1883.
} 
discussão afirmando que a comparação entre sensações não depende, pois, de um ato externo a elas, principalmente porque elas não existem isoladamente. "O que encontramos é um todo indiviso e articulado. Chamaremos estes todos 'estruturas'", afirma Koffka (1922, p. 542).

\section{O impercebido}

À luz dessas precisões conceituais, temos melhores condições de prosseguir na definição de uma concepção estrutural-fenomenológica da percepção, incluindo, a partir de agora, as ideias de percepção inconsciente, ou de impercepção. No que diz respeito a elas, não se trata, como queria Stumpf, de se considerar dados de consciência, ou sensações, despercebidas, mas de atentar para estruturas em que o objeto de percepção se apresenta a partir do contexto perceptivo. Na Fenomenologia da percepção, Merleau-Ponty (1945) afirma que o percebido admite ambiguidades e se deixa modelar pelo contexto. Com efeito, a "sintaxe perceptiva" (Merleau-Ponty, 1945, p. 45) não obedece às regras das relações objetivas. As relações novas estabelecidas por ela, ou seja, os sentidos percebidos, como as experiências plana e dinâmica do exemplo anterior, aderem à configuração dos estímulos, ou, antes, coincidem com a própria configuração. O contexto, fundo perceptivo por excelência, e a regra da configuração parecem ocupar, aqui, o lugar de princípios da percepção não tematizados, embora atuantes. Indicações posteriores, por parte do filósofo, caminham nessa direção.

Veja-se, por exemplo, suas notas de curso no Collège de France, datadas de 1953 e publicadas sob o título de $O$ mundo sensível e o mundo da expressão (Merleau-Ponty, 1953/2011) ${ }^{4}$. Nelas, o autor proporciona novas análises em torno da organização perceptiva, sempre baseadas na Gestalttheorie, embora seja mister mencionar a presença, nestes esboços, de estudos baseados na linguística. A filosofia de Merleau-Ponty pode ser lida pelo viés do seu esforço contínuo de reelaboração teórica acerca da relação entre figura e fundo, exercício de pensamento que atravessa toda sua obra. No final dos anos 1940, após a publicação da Fenomenologia da percepção, um dos elementos conceituais mais mobilizados por Merleau-Ponty é, contudo, o caráter diacrítico do signo linguístico, que advém de uma apropriação livre da sua parte a propósito das teorias do linguista Ferdinand de Saussure. Nessa medida, estabelece-se uma comunicação, na filosofia merleau-pontiana, entre a

\footnotetext{
${ }^{4} \mathrm{O}$ material publicado em $O$ mundo sensível e o mundo da expressão é constituído de notas redigidas por Merleau-Ponty (1953/2011) com o objetivo de fundamentar a comunicação oral das suas ideias nos primeiros cursos que ministrou no Collège de France. Malgrado a atenção que fora dispensada à preparação do curso, sua textualização possui um caráter inacabado e indicativo, que pode ser identificado nas citações diretas das quais nos servimos no presente trabalho.
} 
análise da linguagem e uma nova fenomenologia da percepção (Bimbenet, 2004). Merleau-Ponty (1953/2011) afirma, por exemplo, que os signos, na organização perceptiva, devem ser entendidos como "realizações diversas de uma única potência de variação, que possuem menos existência separada do que existência opositiva e diacrítica" (pp. 117-118), como na fonologia de Saussure. O efeito dessa integração é imprimir sobre o dispositivo gestaltista de figura-fundo uma conotação mais dinâmica, própria da diacriticidade linguística. Segundo Merleau-Ponty (1953/2011), o sentido do percebido emerge como "modulação de uma certa dimensão" (p. 56). Se pensarmos no paradoxo de Stumpf, tem-se que o sentido perceptivo de igualdade ou de diferenciação entre as sensações estabelece-se na variação [écart] em relação a um nível "que não é tema", afirma o filósofo (Merleau-Ponty, 1953/2011, p. 57).

A presença perceptiva do nível é, então, denominada impercepção (imperception), na medida em que funciona, em que possui uma eficácia não tematizada expressamente. Merleau-Ponty (1953/2011) anota: "Toda posição de um em si (figura) pressupõe, lateralmente, posição de um fundo, que, ele, não é objeto, em si - o fundo ou horizonte faz parte da definição do ser" (p. 59). A figura implica um "fundo inarticulado" (p. 59). Quando se tem figura, não se tem o fundo, no sentido de que se deixa o fundo ser sem se pensar nele. É assim que podemos tê-lo. Para Merleau-Ponty (1953/2011), essa discussão se dá no terreno da elaboração de uma teoria da "consciência indireta ou invertida" (p. 59).

A consciência indireta abarca o corpo, ou o esquema corporal, bem como o que Merleau-Ponty (1953/2011) chama de percepção social. Desde Fenomenologia da percepção, Merleau-Ponty dedica-se a discussões sobre a noção de esquema corporal a partir dos aportes teórico-experimentais de autores como Henry Head e Paul Schilder. Em $O$ mundo sensível e o mundo da expressão, um dos sentidos que Merleau-Ponty (1953/2011) dá à noção de esquema corporal é o de "sistema de referência, aqui absoluto, não coisa no espaço ou conteúdo" (p. 129). Remete-se a ele, também, como o "fundo de uma práxis" (p. 134), "o fundo sobre o qual se destacam nossos projetos motores" (p. 131, grifo do autor), de modo que o esquema corporal não pode ser objeto de percepção. Ele é o nível ou norma em relação à qual se expõe um corpo percebido, assim como se apresentam a ele as tarefas para as quais se dirige o tempo todo pré-reflexivamente. Opera, aqui, o registro da impercepção, de uma percepção implícita, do saber sem saber que se sabe, e que, segundo o filósofo, exige a reforma da noção de consciência.

O mesmo vale para a percepção social. O filósofo, nesse ponto, dialoga com a psicanálise freudiana, mais especificamente, com as análises de Freud acerca do 
ciúme, sempre a partir da estrutura figura e fundo ${ }^{5}$. Merleau-Ponty resume as análises freudianas à ideia de que, no ciúme, se tem como figura a rivalidade com um terceiro face à pessoa amada, e como fundo a rivalidade com a pessoa amada em relação a um terceiro. A leitura freudiana exigiria que a figura, relação de natureza heterossexual, fosse tomada como aparência, e que o fundo, uma relação homossexual, fosse tido como realidade inacessível e inconsciente. O processo explicativo envolveria, então, a decifração do inconsciente por reversão das aparências. Merleau-Ponty propõe, por sua vez, que a heterossexualidade e a homossexualidade sejam compreendidas segundo a relação figura e fundo, ou seja, nos termos de uma vinculação por implicação recíproca. Neste caso, não se pode dizer que o fundo seja mais verdadeiro que a figura, ou vice-versa. "Ser heterossexual é ser homossexual mediatamente", anota Merleau-Ponty (1953/2011, p. 61), de modo que a heterossexualidade e a homossexualidade constituem "estruturações possíveis do conjunto figura e fundo" (p. 61). A predominância de uma estruturação não comporta a anulação da outra, que subsiste a título de fundo. Neste quadro, podemos ter "tanto homossexualidade-figura sobre fundo de heterossexualidade, tanto o inverso", "como nas figuras ambíguas dos gestaltistas", completa Merleau-Ponty (1953/2011, p. 60). Não há, portanto, para o filósofo, inconsciente como sentido inacessível, mas como ambiguidade das figuras ${ }^{6}$.

A conclusão desse trecho de anotações e esboços rearranja a categoria da consciência intencional: "A consciência como consciência de qualquer coisa sempre enganosa ou enganada: ela não é consciência disso senão sendo também consciência daquilo e não assumindo o aquilo. Ela vesgueia [Elle louche]" (Merleau-Ponty, $1953 / 2011$, p. 61, grifo do autor). A percepção não se resume, portanto, ao contato com algo lançado diante de nós, um ob-jeto. Ela expressa a "modulação de um fundo" (p. 60), sem o qual não há figura. A função estrutural do fundo, presente a título de impercebido, é o que Merleau-Ponty chama de mutismo da percepção.

\footnotetext{
${ }^{5} \mathrm{Em}$ nota, os organizadores dos cursos publicados em $O$ mundo sensível e o mundo da expressão indicam que Merleau-Ponty (2011) provavelmente se baseara no texto de Freud intitulado Über einige neurotische Mechanismen bei Eifersucht, Paranoia umd Homosexualität [Alguns mecanismos neuróticos no ciúme, na paranoia e no homossexualismo], publicado originalmente em 1922.

${ }^{6}$ É oportuno observar que a filosofia de Merleau-Ponty vem sendo revisitada com o intuito de embasar discussões sobre gênero e sexualidade. A respeito do assunto, sugerimos a leitura do trabalho de Ayouch (2017), que além de possuir um caráter propositivo acerca dessas questões, apresenta indicações relevantes sobre a literatura disponível em torno de reflexões sobre gênero e sexualidade com base em Merleau-Ponty.
} 


\section{O problema funcional}

Resta tratar da organização perceptiva a partir dos aspectos funcionais da percepção. Confrontamo-nos, aqui, com o problema dos critérios segundo os quais se dá o ato intencional de visar eletivamente alguma coisa. A estruturação do mundo perceptivo, com a presentificação de figuras e a modulação do fundo, depende, primeiramente, do que Merleau-Ponty (1942/2006), em seu livro de estreia, chama de estruturas do comportamento. No que diz respeito à estrutura de comportamento humana, chegaremos à formulação de uma hipótese de investigação, relativa ao papel do outro na percepção.

É comum que os determinantes da percepção sejam divididos em duas grandes categorias: os estruturais e os funcionais. Por fatores funcionais da percepção entendem-se aqueles que derivam, primordialmente, do sujeito perceptivo, tais como necessidades e experiências passadas, enquanto os caracteres estruturais referem-se aos fatores da organização perceptiva próprios dos elementos presentes no campo ambiental de percepção, tais como semelhança e contraste, simplicidade e regularidade etc. Igualmente recorrente é a afirmação de que os psicólogos da Gestalt dedicaram-se, basicamente, aos determinantes estruturais da percepção, negligenciando os fatores funcionais. Não é difícil, contudo, estabelecer a arbitrariedade daquela distinção, bem como identificar nos trabalhos dos principais expoentes da psicologia da Gestalt considerações decisivas acerca do papel, na percepção, de fatores tais como as características do organismo, a natureza do ego e a aprendizagem (Luchins, 1951).

No que diz respeito a Merleau-Ponty, não se pode afirmar que o filósofo trabalhe com a separação entre os aspectos estruturais e funcionais da percepção, nem que denuncie esta divisão nos trabalhos da psicologia da Forma. Suas críticas aos psicólogos da Gestalt centram-se na teoria do isomorfismo, adotada por eles. Segundo esta teoria, considerando que se encontram formas no universo físico, por exemplo, na distribuição de corrente elétrica em condutores elétricos, as formas vividas podem ser reduzidas a "réplicas interiores de formas externas do mundo físico, por intermédio das formas do sistema nervoso" (Merleau-Ponty, 1958/2001, p. 441). Neste caso, o mundo fenomenal seria a expressão de fenômenos de forma no sistema nervoso. Esta assunção naturalista implica, segundo Merleau-Ponty (1942/2006), o abandono do exercício de realização de uma filosofia da forma. Deixa-se de pensar segundo a categoria de forma, na medida em que não se pergunta pelas possibilidades ontológicas que o conceito de forma exige, além de subsumir as estruturas biológicas e psíquicas a estruturas físicas. 
A resposta de Merleau-Ponty ao isomorfismo delineia-se a partir da aproximação com autores como von Weizsäcker, Buytendijk, Uexküll e, principalmente, Kurt Goldstein, que se dedicaram, em grande medida, a determinar as especificidades do comportamento animal e humano face ao mundo físico. Uma breve apreciação das análises merleau-pontianas baseadas nos trabalhos de Goldstein nos levará ao problema dos aspectos funcionais da percepção mediante discussões acerca do comportamento animal e do comportamento humano.

Goldstein (1934/1983) pergunta: "por que uma coisa é uma forma, uma Gestalt?" (p. 298), "o que produz a forma?" (p. 299). Sabe-se que o organismo não reage às qualidades particulares de uma situação, mas aos seus aspectos estruturais, no sentido da teoria da Gestalt. É justamente o todo da situação que pode ser transposto. Köhler (1929/1980) relata experimentos sobre a invariabilidade das formas percebidas sob transposição em animais. Macacos e galinhas que aprenderam a escolher o mais escuro dentre dois objetos, quando expostos a um novo par de objetos, e de cuja composição participa o objeto mais escuro da série anterior, apenas o escolhem caso ele seja o mais escuro do novo par. Segundo Köhler (1929/1980), fatos como este evidenciam que, "entre o estímulo e a reação, ocorre o processo de organização, em particular a formação de unidades-grupo em que as partes adquirem novas características" (p. 118). Merleau-Ponty (1942/2006), ao analisar estes experimentos, afirma que a presença objetiva do estímulo não constitui, necessariamente, uma parte real da situação. Em outras palavras, a eficácia de um estímulo não é determinada pela sua presença objetiva, mas pelo seu papel na configuração em que ele aparece. Este é o componente autóctone da estrutura da percepção, e está de acordo com a crítica da hipótese de constância. Mas isso não é tudo. É preciso considerar, como destacam Goldstein e Merleau-Ponty, as próprias estruturas orgânicas, que constituem unidades de significação distintas pelo caráter transitivo que revelam em relação ao ambiente. O equilíbrio da estrutura percebida não depende, nesse caso, tão somente de "condições presentes e reais", mas de condições "virtuais", diz Merleau-Ponty (1942/2006, p. 157), trazidas à existência pelo próprio sistema orgânico. O filósofo acrescenta: a estrutura "executa um trabalho fora de seus próprios limites e constitui para si um meio próprio" (Merleau-Ponty, 1942/2006, p. 157). O meio de experiência é investido pelo organismo com significações vitais, de modo que a reação do organismo a uma situação global ocorre mediante a interiorização do meio pelo organismo, ou pela expressão, no meio, da "lei interior do organismo" (Merleau-Ponty, 1942/2006, p. 174).

Esta análise funcional-biológica da percepção por parte de Merleau-Ponty encaminha-se para o problema da passagem da estrutura de comportamento animal à estrutura de comportamento humana. O conceito de multiplicidade perspectiva 
orienta as duas dimensões diferenciais abertas por Merleau-Ponty (1942/2006) n'A estrutura do comportamento: a que distingue a forma simbólica de comportamento, própria do homem, das formas sincréticas e amovíveis, e a que separa a ordem humana da ordem vital. Ambas denotam a intenção de discriminar a diversidade de expressões de um perspectivismo radical (Bimbenet, 2011), marca do comportamento ou da percepção animal em comparação à liberdade da percepção humana. Verificase, no comportamento animal, uma aderência imediata ao meio na medida dos a priori da sua espécie, com a polarização irremediável de todo aparecimento perceptivo sobre si. O meio animal, o seu Umwelt, apenas pode aparecer a partir da perspectiva biológica de cada espécie animal. Caso tomemos o cuidado de buscar compreender o animal a partir do seu modo próprio de ser, e não a partir de um mundo objetivo, concebido pelo homem, poderemos constatar que o ponto de vista do animal possui um caráter constituinte: ele "institui ativamente um ambiente" (Bimbenet, 2011, p. 178) e, com base nessa visibilidade aberta, recebe "as informações que Ihe concernem" (p.178). É nesse quadro que se estabelece a percepção e a impercepção, a figura e o fundo possíveis da experiência animal, o gênero de ser que lhe compete. As experiências com chimpanzés relatadas por Köhler (1927) são expressivas a este respeito. Os símios antropoides, especialmente os chimpanzés, diferentemente de qualquer outra espécie animal, são capazes de estabelecer relações mecânicas entre os meios e os fins de uma ação. Essa atividade depende de treino. Köhler habituou alguns chimpanzés a utilizar bastões para alcançar alimentos colocados do lado de fora de suas jaulas, e distantes do alcance dos braços. Numa variação dos experimentos, os animais não tinham nenhum bastão à disposição. Dentro da jaula, contudo, havia uma árvore, distante das grades, com três grandes galhos saindo do tronco. Alguns dos animais, depois de explorarem bastante a jaula, tentando utilizar, inclusive, barras da grade, dirigem-se, enfim, para a árvore, arrancam um galho e alcançam seu alimento. Köhler (1927), analisando a situação experimental, faz menção à dificuldade, para os animais, de "ver um galho como bastão isolando-o da árvore" (p. 99, grifo nosso). A árvore, inicialmente, é vista como um todo. A reconfiguração visual do espaço e, principalmente, do objeto percebido, que envolve o destacamento do galho como figura, implica a solução do problema ao qual os chimpanzés se encontram expostos. Ela depende de possibilidades próprias da espécie e, igualmente, da aquisição do hábito de utilização de bastões. Animais não treinados jamais chegam a estabelecer um tal valor de uso aos bastões e galhos de árvore, e, portanto, jamais atingem aquela solução.

O comportamento humano, ao contrário, caracteriza-se, logo cedo no processo ontogenético, pelo descentramento na direção da constância e, mais além, da objetividade da coisa percebida. No experimento em questão, é lícito considerar que, 
para o chimpanzé, o braço de árvore, a partir do instante em que adquire o valor funcional de bastão, é suprimido como galho de árvore. No caso do homem, afirma Merleau-Ponty (1942/2006), "o galho de árvore transformado em bastão continuará justamente um galho-de-árvore-transformado-em-bastão" (p. 190), ou seja, uma única coisa com funções diferentes, "visível 'para ele' sob uma pluralidade de aspectos" (p. 190, grifo do autor). Outra maneira de se referir à propriedade objetiva que as coisas podem adquirir para o olhar humano é dizer, como o faz Merleau-Ponty, que as propriedades físico-geométricas do galho "estão virtualmente presentes nos estímulos" (p. 124). No caso dos chimpanzés, por outro lado, estas relações jamais aparecem em estado puro, além de pressupor uma estruturação inédita da situação, facilmente encoberta por conexões biológicas mais fortes e estáveis. Não afirmamos, evidentemente, que o mundo humano seja constituído por conexões físicogeométricas, mas que, mediante uma modificação da nossa atitude natural, o mundo pode apresentar-se como mundo real e objetivo. Em outras palavras, este mundo objetivo é um gênero de ser que integra nosso campo de presença e que pode, naturalmente, configurar estruturas do tipo figura e fundo. Pode-se afirmar, ainda, que o mundo real e objetivo é um fundo de presença disponível para nós. O equívoco, muito bem apontado por Merleau-Ponty, seria tratar a representação objetiva do mundo como realidade primeira, e, daí, explicar o comportamento e a consciência perceptiva a partir dele, quando, ao contrário, esta representação figura em nossa experiência como uma atitude possível por parte do sujeito da percepção.

O fato é que, mais do que uma presença natural do mundo, no sentido do cientificismo, orientamo-nos para a presença de uma realidade múltipla e independente de nós, atitude que Bimbenet (2011) denomina realismo. É apenas com algum esforço que suspendemos esta atitude natural para notarmos que a multiplicidade perspectiva ainda é uma perspectiva, uma forma de olhar, ou, justamente, uma atitude. Mais do que isso, é preciso considerar que continuamos sendo capazes de perceber implicitamente, sem saber que sabemos, ou de ver apenas aquilo que importa ou aquilo que podemos ver, permanecendo cegos para todo o resto (Bimbenet, 2011). Isso quer dizer que a função objetivante, ou presentacional, da estrutura figura e fundo, permanece condicionada a significações funcionais possíveis. Como definir, então, aquilo que escapa aos esquemas funcionais? A ideia de horizonte pode se revelar uma saída para o impasse, desde que recordemos que, para os fenomenólogos, o horizonte é, no limite, o próprio mundo, aquele da atitude realista, e que é vivido de forma intersubjetiva, ou social. O que me escapa pode não escapar ao outro. No outro, sobrevive a possibilidade de apresentação de novos objetos, de novos costumes, de novos códigos sociais, de novas perspectivas de percepção. 


\section{Considerações finais}

Nossa procura por fundamentos para uma concepção estrutural-fenomenológica da percepção a partir de Merleau-Ponty centrou-se em três pontos principais. $O$ primeiro deles refere-se à exploração da relação entre a propriedade presentativa da percepção e o campo da sua manifestação a partir de pressupostos fenomenológicos e gestaltistas. Na descrição fenomenológica da percepção, a manifestação perceptiva de objetos se dá num horizonte perceptivo, e, por isso, envolve uma dinâmica de aparecimento e de encobrimento. O recuo dos horizontes interno e externo dos objetos denota a dimensão corpórea e, principalmente, motora da percepção. Esses princípios são compatíveis com a estrutura de figura e fundo, investigada teórica e experimentalmente pela psicologia da Gestalt. O segundo ponto baseia-se na crítica à hipótese de constância, que remonta aos esforços do movimento gestaltista para ultrapassar o sensualismo e estabelecer os pressupostos fundamentais da atividade perceptiva como configuração do campo de percepção. Os preceitos fenomenológicos correlacionados aos conceitos científicos gestaltistas permitem que Merleau-Ponty explore a fecundidade da relação entre aquilo que aparece e o seu contexto de aparecimento. Constata-se que o fundo perceptivo age sem que o sujeito da percepção se atenha a ele. Essa operância silenciosa constitui a dimensão do impercebido, a que se refere o filósofo. O princípio da impercepção pode ser estendido, por exemplo, à presença do corpo no campo de percepção e às nossas vivências sociais. Por fim, num terceiro ponto, mostramos que o campo de percepção envolve fatores funcionais. O arranjo gestáltico da presentificação do objeto percebido e do seu contexto perceptual depende de condições estruturais referentes ao sujeito percipiente e às suas condições concretas de percepção. Nessa medida, e no que diz respeito à percepção humana, não se pode deixar de considerar a multiplicidade perspectiva como uma forma de olhar, em que se atualiza o modo mais próprio da nossa estrutura de comportamento. Esta, contudo, é igualmente determinada por nossos estágios de maturação psicológica, nossa história de estruturação da personalidade, nossos costumes sociais etc. Todavia, na condição de seres que partilham um mundo comum, observa-se, continuamente, a participação do outro na reconfiguração do nosso campo de presença. O outro desafia nossos esquemas, nossas estruturas psíquicas cristalizadas e nossos hábitos sociais, de maneira que a intersubjetividade emerge como tema de primeira importância no avanço das pesquisas sobre percepção. 


\section{Referências}

Ayouch, T. (2017). Merleau-Ponty's non-exclusively-verbal unconscious: affect figurability and gender. Em D. Legrand \& D. Trigg (Orgs.). Unconsciousness between phenomenology and psychoanalysis (pp.181-207). Cham, Suíça: Springer

Barbaras, R. (2001). Merleau-Ponty et la psychologie de la forme. Les Études Philosophiques, 57(2), 151-163.

Bimbenet, E. (2004). Nature et humanité: le problème anthropologique dans l'ouvre de Merleau-Ponty. Paris: Vrin.

Bimbenet, E. (2011). L'animal que je ne suis plus. Paris: Gallimard.

Colonna, F. (2014). Merleau-Ponty et le renouvellement de la mátaphysique. Paris: Hermann.

Goldstein, K. (1983). La structure de l'organisme (E. Burckdardt \& J. Kuntz, Trads). Paris: Gallimard. (Original publicado em 1934).

Gurwitsch, A. (1957). Théorie du champ de la conscience. Bruges, Bélgica: Desclée de Brouwer.

Koffka, K. (1922). Perception: an introduction to the gestalt-theorie. The Psychological Bulletin, 19(10), 531-585.

Koffka, K. (1975). Princípios de psicologia da Gestalt (A. Cabral, Trad.). São Paulo: Cultrix. (Original publicado em 1935).

Köhler, W. (1927). L'intelligence des singes supérieurs (P. Guillaume, Trad.). Paris: Félix Alcan. (Original publicado em 1925).

Köhler, W. (1980). Psicologia da Gestalt (D. Jardim, Trad.) (2a ed.). Belo Horizonte: Itatiaia. (Original publicado em 1929).

Luchins, A. (1951). An evaluation of some current criticisms of gestalt psychological work on perception. Psychological Review, 58(2), 1951.

Merleau-Ponty, M. (2006). La structure du comportement. Paris: PUF. (Original publicado em 1942).

Merleau-Ponty, M. (1945). Phénoménologie de la perception. Paris: Gallimard.

Merleau-Ponty, M. (1996). Le primat de la perception et ses conséquences philosophiques. Lagrasse: Verdier. (Originais publicados em 1933-46). 
Merleau-Ponty, M. (2001). Les sciences de I'homme et la phénoménologie (pp. 397464). Em M. Merleau-Ponty. Psychologie et pédagogie de l'enfant: cours de Sorbonne: 1949-1952. Lagrasse: Verdier. (Original publicado em 1958).

Merleau-Ponty, M. (2011). Le monde sensible et le monde de l'expression: cours au Collège de France, notes, 1953. Genève: Metispresses. (Originais de 1953).

Silva, C. (Org.). (2015). Kurt Goldstein, psiquiatria e fenomenologia. Cascavel, Paraná: Edunioeste.

Simondon, G. (2013). Cours sur la perception: 1964-1965. Paris: PUF. (Orignais de 1964-5, publicado postumamente em 2006).

\section{Nota sobre o autor}

Danilo Saretta Verissimo. Docente na Universidade Estadual Paulista "Júlio de Mesquita Filho", Campus Assis. E-mail: danilo.verissimo@gmail.com 